WIENER SLAVISTISCHES JAHRBUCH, Band 57/2011, 165-178

(C) 2011 by Österreichische Akademie der Wissenschaften, Wien

JOHANNES REINHART

\title{
Die Chronologie der Entstehung der sekundären Jerlaute im Serbokroatischen (Bosnischen, Kroatischen und Serbischen)
}

Die Jerlaute sind eine charakteristische Besonderheit des urslawischen Vokalsystems. Es sind hohe, kurze Vokale, die aus kurzem $\breve{l}$ und kurzem $\breve{u}$ entstanden sind, wobei der hintere Jerlaut $b(<* \breve{u})$ die Rundung verloren hat. Mit ihrer Veränderung, d. h. ihrer Vokalisierung bzw. ihrem Schwund, endet nach geläufiger Ansicht die gemeinslawische Spracheinheit. ${ }^{1}$ In den slawischen Gegenwartssprachen gibt es auch Reflexe von Jerlauten, die erst später entstanden sind und die man deshalb meist sekundäre Jerlaute nennt. Sie sind zwischen Konsonanten und Sonanten, meist am Wortende, manchmal auch innerhalb des Wortes, entstanden. Die Bedingung für ihre Entstehung war die Veränderung der Silbenstruktur, die sich durch den Ausfall der am Wortende stehenden Jerlaute ergab. Die Unterscheidung zwischen primären und sekundären Jerlauten ist auf der Grundlage der Gegenwartssprachen nicht möglich. Es gibt vier Kriterien, nach denen man entscheiden kann, ob in einem Wort ein Jerlaut sekundär ist (war) oder nicht:

(1) Altkirchenslawisch; im Altkirchenslawischen gibt es normalerweise noch keine sekundären Jerlaute;

(2) die ältesten altostslawischen Sprachdenkmäler (bis zum Beginn des 12. Jh.); auch im ältesten Altostslawischen gibt es kaum sekundäre Jerlaute;

(3) in Einzelfällen phonotaktische Kriterien;

(4) der Vergleich mit anderen indogermanischen Sprachen.

Aus den angeführten Kriterien folgt, dass es manchmal nicht möglich ist, zwischen primären und sekundären Jerlauten zu unterscheiden. Dies ist dann der Fall, wenn ein Wort weder im Altkirchenslawischen noch in den ältesten ostslawischen

${ }^{1}$ Vaillant 1950: 125, Shevelov 1964: 462 (§ 29, 14), Mareš 1991: 9, Schenker 1993: 78 (§ 2.25), Schenker 1995: 97 (§ 2.38.). 
Sprachdenkmälern belegt ist, und es auch keine - genauen - Parallelen in anderen indogermanischen Sprachen gibt.

Andererseits werden in der Literatur immer wieder irrtümliche sekundäre Jerlaute zitiert, da man die vier Kriterien nicht beachtet. Als Beispiele seien folgende Wörter angeführt: †ogls 'Ecke', †svekrъ 'Schwiegervater, Vater des Ehemannes' und $\dagger$ †ichrs 'Sturmwind, Wirbelwind'. ${ }^{2}$ In Wirklichkeit sind sie folgendermaßen zu rekonstruieren: * ${ }^{*} g b l b,{ }^{*}$ svekъrb und *vichъrb. Im Falle des ersten und zweiten Wortes ist der Vergleich mit anderen indogermanischen Sprachen relevant (vgl. lat. an-


Wort *vichbrb ist die Phonotaktik entscheidend (die Kombination -chr- kann hier nicht ursprünglich sein, das $c h$ hätte vor $r$ ausfallen müssen) ${ }^{3}$. Bei ${ }^{*}$ ogъlъ kommt noch die Evidenz der aksl. Denkmäler hinzu: einem einzigen Beispiel ohne Vokal zwischen $g$ und $l$ ( $г л-$ aus der Savvina kniga; Mt 21.42) stehen neun mit einem Jerlaut bzW. mit -o- dazwischen gegenüber, und zwar жгъл-/кгьл-/кгол-. ${ }^{4}$

Ein Wort, dessen Ansatz auf Grund der ungünstigen Beleglage schwierig ist, ist das urslawische Wort für den 'Knoten'. Es lautet in den slawischen Gegenwartssprachen folgendermaßen: russ. узел, ukr. вузол, wruss. вузел, poln. wezzet, osorb. wuzol, tschech. uzel, slk. uzol, sln. vozel, kroat./serb. uzao, mak. јазол, bulg. възел; роlab. vqzal. Es wurden folgende urslawischen Vorformen vorgeschlagen: ${ }^{*} q z l_{b}{ }^{5}$, ${ }^{*} Q z b l b^{6},{ }^{*} Q z z l b^{7}$. Manche Autoren rekonstruieren Doppelformen. ${ }^{8}$ Für die Entscheidung zwischen diesen Varianten irrelevant sind das Tschechische, Slowenische,

2 Vgl. z. B. Meyer 1923: 250, 252; Issatschenko 1970: 78, 80; Issatschenko 1980: 146, 147 ; Flier 1993: 250, 258; Derksen 2008: 475 (s. v. svekrb m. 'father-in-law (husband's father)'); Matasović 2005: 365, 372; Matasović 2008: 147 (§ 163). - Der Ansatz *svekrb ist auch dann nicht berechtigt, wenn man annimmt, *suekruh $2^{-}$'Schwiegermutter' (< *suekurh $2^{-}$, s. Mayrhofer 1986: $\left.162, \S 7.3 .1\right)$ hätte sein palatales *k zuerst vor unmittelbar folgendem - $r$ - depalatalisiert, und darauf hätte *suekuro- 'Schwiegervater' diese Veränderung analogisch mitgemacht. Das Prager aksl. Wörterbuch setzt irrtümlicherweise свєкрz an, obwohl dort nur ein Beleg aus einer russ.-ksl. Hs. des 14. Jh. zitiert wird (свєкорz, SJS IV: 24; um ein Jahrhundert älter ist der Beleg aus dem Sammelband RNB, Q. ח. I. 18, 156v4: свєкъръ, Wątróbska 1987: 156). - Das Zeugnis des Alttschechischen und Altpolnischen ist widersprüchlich: das Alttschechische hat svekr (Mammotrekt A, Olmützer Bibel, Životy svatých otců), das Altpolnische świekier (der Nom. Sg. zeigt laut SłStp IX: 62 f., s. v. Świekier etc. folgende Beleglage: świokier [1x], świekier [2x] vs. świekr [1x]). Vermutlich hat das Alttschechische die Stammform des femininen svekrev verallgemeinert.

3 Vgl. außerdem die Formen in den altrussischen Handschriften der Pandekten des Antiochus (11. Jh.; внхвръ, Popovski 1989: 60, 36:26) und im Sinaitischen Paterikon (11./12. Jh.; f. 40.7: внхъръ, Golyšenko - Dubrovina 1967: 115).



5 Z. B. Miklosich 1862-1865: 1164, s. v. жZ^ъ; Klemensiewicz - Lehr-Spławiński - Urbańczyk 1955: 116; Vaillant 1974: 550 (§ 1050); Issatschenko 1980: 147; Snoj 2003: 831, s. v. vozel.

6 BER 1: 203, s. v. въ̀зел $(*(v) Q z b l b)$.

7 Olesch 1984: 1545, s. v. Wûnsále.

8 Kopečný 1981: 254, s. v. QZ(Ъ)LЪ; Schuster-Šewc 1988: 1715, s. v. wuzoł (*vQz(b)lъ). 
Kroatische und Serbische sowie das ausgestorbene Polabische ${ }^{9}$. Das Zeugnis des Russischen, Weißrussischen und Ukrainischen ist widersprüchlich. Jedoch hatte auch das ältere Russische die Form узол. Diese ältere russische Form, russische Dialektformen und das Ukrainische weisen auf die Vorform ${ }^{*} Q z ъ l b .{ }^{10}$ Ebenso kann das poln. węzet auf diese Form zurückgeführt werden (möglich wäre auch * $Q z l$, ausgeschlossen bleibt * $Q z b l b$, das †węziet ergeben hätte). Auch mak. јазол ist auf * ${ }^{2}$ lъ $_{\mathrm{b}}$ oder ${ }^{*}$ gzъlb zurückzuführen. Dieser Rekonstruktion widerspricht lediglich bulg. възел. * ${ }^{*}$ ъъ keine älteren Belege für das Wort im Bulgarischen. Es ist denkbar, dass hier eine Angleichung an Wörter mit dem Suffix -el vorliegt. Ein analoger Fall liegt wahrscheinlich dem bulg. въ̀бел 'Quelle, Brunnen' (vgl. BER 1: 200) zugrunde, das sicher - vgl. russ.-ksl. оуволъ (Sinaitisches Paterikon, 57r11, 57r20; Golyšenko - Dubrovina 1967: 149) - auf * $Q b b l$ z zurückgeht. Auf Grund der slawischen Evidenz lautet das urslawische Wort für den 'Knoten' also *Qzъlъ.

Wenn man die Vollständigkeit der Durchführung des Einschubs der sekundären Jerlaute in den slawischen Sprachen betrachtet, so heben sich deutlich diejenigen Sprachen, die diese Regel ausnahmslos durchgeführt haben, von denjenigen ab, die sie mit mehr oder weniger Ausnahmen durchgeführt haben. Die slawischen Sprachen mit ausnahmsloser Durchführung des Einschubs sekundärer Jerlaute sind alle südslawischen Sprachen, das Slowakische ${ }^{11}$ und das ausgestorbene Polabische ${ }^{12}$. Die slawischen Sprachen zeigen also hier Resultate, die nicht mit der Einteilung in die Sprachgruppen übereinstimmen müssen: Slowakisch, in gewissem Ausmaß auch das ausgestorbene Polabische, sind in dieser Hinsicht den südslawischen Sprachen näher. Die westslawischen Sprachen ${ }^{13}$ - mit Ausnahme des Slowakischen und Polabischen - und die ostslawischen Sprachen ${ }^{14}$ kennen Ausnahmen beim Jereinschub. Die zahlreichsten Ausnahmen sind in den westslawischen Sprachen vorhanden. Außerdem ist für diejenigen Sprachen mit einer längeren schriftlichen Bezeugung (Polnisch, Tschechisch) charakteristisch, dass es in den ersten Jahrhunderten der schriftlichen Bezeugung noch weniger Beispiele mit Einschub gab. ${ }^{15}$ So begegnen uns im

9 Allerdings entwickeln sich die sekundären Jerlaute in den wenigen polabischen Beispielen als $\check{e}$ (pesĕn 'Lied', siděm '7', visĕm '8'; Ausnahme sind die lautgesetzlichen Reflexe als $i$ nach Velar und vor labialen sowie dentalen Konsonanten: vid'in 'Feuer' < *ognb, vod'il 'Kohle' < $q g l b$ ), während die Jerlaute als $\breve{a}$ reflektiert sind (vgl. Olesch 1983: XXVII; z. B. gornăk 'Milchtopf' <*gъrnъkb, polăc 'Finger, Zehe' <*palbcb).

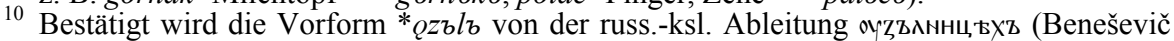
1906: 51.6; <* ${ }^{*} z$ ъlbnikъ) aus der Efremovskaja Kormčaja (11./12. Jh.).

11 Vgl. Stanislav 1956: 321-324, Pauliny 1958, Pauliny 1963: 129 ff. (§ 18).

12 Vgl. polab. pesěn, vid' in 'Feuer', visĕm '8', vod' il 'Kohle'.

13 Vgl. poln. bóbr, pieśń, wewnatrz, wiatr, wieprz, zmyst; tschech. bratr, kopr, mysl, vitr (vgl. auch Gebauer 1894: 151, § 135, 160, § 141; Mareš 1977: 220).

14 Vgl. russ. вепрь, мёртв, молитв (Gen. Pl.), мыссль, трезв; ukr. вепр, зубр, смисл.

15 Rozwadowski 1915: 345 (§ 33.b.), Klemensiewicz - Lehr-Spławiński - Urbańczyk 1955: 116, Lamprecht - Šlosar - Bauer 1986: 78 (5.4.). 
Alttschechischen noch Formen wie bázn ${ }^{16}, k a ́ z n^{17}$ und sestr (Gen. Pl.) ${ }^{18}$, während das heutige Tschechische Formen mit Einschub hat, also bázě̌, kázě̆ und sester. Ebenso kommt im Altpolnischen biodr (Gen. Pl.), gardt (Gen. Pl.), ośm '8', siedm '7', skrzydt (Gen. Pl.), sosn (Gen. Pl.), widt (Gen. Pl.) vor ${ }^{19}$, während das heutige Polnische bioder, gardet, osiem, siedem, skrzydet, sosen, widet hat.

Nicht bei allen slawischen Sprachen ist es möglich, die Chronologie der Entstehung der sekundären Jerlaute genau zu verfolgen, da sich aus dem Zeitraum, in dem sich der Prozess abgespielt hat, keine Sprachdenkmäler erhalten haben. Trotzdem kann man mit einiger Sicherheit annehmen, dass die Epenthese zuerst im Slowenischen stattgefunden hat. ${ }^{20}$ Wahrscheinlich erst zu Beginn des 12. Jh. entwickelten sie sich in den ostslawischen Sprachen. Auf Grund allgemeiner Überlegungungen Sprachdenkmäler gibt es leider nicht - ist davon auszugehen, dass sie sich im Tschechischen und Polnischen im 11. und 12. Jh. entwickelt haben.

Bevor wir uns der Frage der Chronologie der Entstehung der sekundären Jerlaute im Serbokroatischen (Bosnischen, Kroatischen und Serbischen) zuwenden wollen, kurz einige Bemerkungen über diese Chronologie in den übrigen slawischen Sprachen. Das Altkirchenslawische kennt noch keinen Jer-Einschub. Die zwei Beispiele, die man anführt, těseñ $ъ$ aus dem Assemani-Evangelistar (123a1; Mt 7.14) ${ }^{21}$ und vědẹrъ aus dem Euchologium sinaiticum (20b6) werden meist als analogisch erklärt. ${ }^{22}$ Diesen zwei Beispielen gesellen sich zwei Beispiele aus dem spät-aksl. ergänzten


(Mt 18.21, 22.28). Weitere aksl. Beispiele sind nicht bekannt. Diejenigen, die man in der Literatur findet, beruhen auf unrichtigen Ansätzen. Dies betrifft die Lexeme

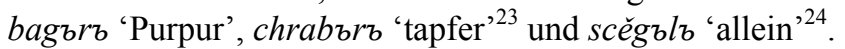

Die ersten altostslawischen Beispiele stammen aus dem 12. Jahrhundert: Toržestvennik/Zlatoust RNB, F.п.I.46 (147vb18: въ_.ь॰pz [Georgieva 2003: 227],

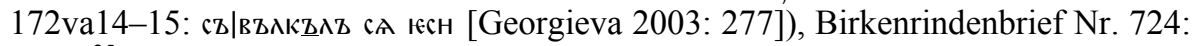
осьмь. ${ }^{25}$ Ebenso aus dem 12. Jahrhundert stammen die ersten mittelbulgarischen Bei-

16 Gebauer 1894: 161 (§ 143), Gebauer 1903: 30, s. v. bázn etc.

17 Gebauer 1894: 161 (§ 143), Gebauer 1916: 27 f., s. v. kázn etc.

18 Gebauer 1894: 165.

19 Beispiele aus dem altpolnischen Wörterbuch.

20 Vgl. Reinhart 2002.

21 Diels 1932: 105 (§ 29, Anm. 4).

22 Vaillant 1964: 79 (§ 49d), Koneski 1967: 55.

23 S. Kopečný 1981: 130, s. v. CHORBRЪ; SJS IV: 789 f., ss.vv. храврz ${ }^{1}$, храврz ${ }^{2}$, храврьскъы, храврьство; Cejtlin - Večerka - Bláhová 1994: 764, ss. vv. хравръ, храБрьскъы. Richtig Vaillant 1974: 651, § 1127 (xrabŭrŭ).

24 S. ESJS 13, s. v. scěglъ.

25 Ein Beispiel begegnet schon im 11. Jh. (Izbornik vom Jahr 1073, f. 37b12: sedbmb). Ganz aus dem Rahmen fallen die 23 Vorkommen des Hilfszeitwortes (1. Pers. Sg.) esъmъ im „Zakon Iisusa Christa“ des „verborgenen Textes“ („скрытый текст“) des Novgoroder Kodex aus dem 1. Viertel des 11. Jh. (vgl. Zaliznjak - Janin 2001: 24). 
spiele. ${ }^{26}$ Älter sind die ältesten slowenischen Beispiele aus den Freisinger Denkmälern (972-1039): /jesəm/ (drei verschiedene Schreibungen: 〈gezim〉 [1x 1. Pers. Sg.; $1 x$ 1. Pers. P1.], 〈iesem〉 [1x 1. Pers. Sg.], 〈iezem〉[4x 1. Pers. Sg.] $)^{27}$, /pokazan/ $(\langle$ pocazen $\rangle){ }^{28}$ Keine exakte chronologische Aussage erlauben das Tschechische und Polnische, da dort bis zum 13. bzw. 14. Jh. keine Sprachdenkmäler bekannt sind. Einen indirekten Hinweis gibt hier bloß die vermutete Chronologie des Ausfalls der schwachen Jerlaute. Dieser wird für das Tschechische im 10. Jh. ${ }^{29}$, für das Polnische am Übergang vom 10. zum 11. Jh. ${ }^{30}$ angenommen. Jedoch ist dies klarerweise nur ein Terminus post quem. Die ersten alttschechischen bzw. altpolnischen Schriftdenkmäler bieten bereits einige Beispiele, z. B. der alttschechische Museumspsalter (13. Jh. ${ }^{31}$; piesen $\langle\mathrm{s}\rangle$ kým - psalmi, 97.5; sem smýšlel - proposui, 130.2) oder die altpolnischen Gnesener Predigten sowie der Florianer Psalter ${ }^{32}$. Wie eben festgestellt wurde, entwickelten sich im Tschechischen und Polnischen manche der sekundären Jerlaute erst spät. Jedoch ist davon auszugehen, dass der Beginn ihrer Entwicklung im 11. bis 12. Jh. anzusetzen ist. Bei den Sprachen ohne ältere Schriftdenkmäler (Polabisch, Slowakisch, Sorbisch) kann man nur vermuten, dass die Chronologie der Jerepenthese ähnlich wie in den nächstverwandten Sprachen verlief.

In diesem Aufsatz wollen wir die Entstehung und Ausbreitung der sekundären Jerlaute im Bosnischen, Kroatischen und Serbischen näher betrachten. Im Bosnischen, Kroatischen und Serbischen ist die Epenthese im Laufe des 12. Jh. bereits belegt. Wir verfügen über einen Artikel von Milan Rešetar aus dem Jahre 1921, der die sekundären Jerlaute im Serbokroatischen behandelt, in dem jedoch die chronologische Seite der Frage kaum zur Sprache kommt. Sehr wichtig ist die vollständige Dokumentierung und Analyse der kroatisch-glagolitischen Fragmente des 12. und 13. Jh. durch den Zagreber Slawisten Milan Mihaljević (Mihaljević 2000, Mihaljević

${ }^{26}$ Dobromir-Evangelium (11./12. Jh.): сє |дьмь (10б9-10; Mc 12.23) (s. schon Jagić 1898: 42 f.); Apostolus von Slepče (12. Jh.): Авврн, А внстввно, єсъмд, ндоложрътввнад,

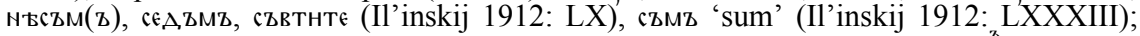
Grigorovič-Parimejnik (12./13. Jh.; fast kein Beispiel in der letzten Silbe): $\mathrm{A} \Gamma \mathrm{z} \mathrm{z}$ (30r11;


16.24), жрътъвнаға (58r27; Pr 21.3), клаттвнаго (62r21; Gn 46.5), зъмна (63r6; Pr 23.32), вZъвнн (63v21; Is 66.16). Zum heutigen Makedonischen vgl. Mareš 1981-1982.

27 Darüber hinaus kennen die Freisinger Denkmäler einen Beleg ohne Jer-Epenthese: 〈gezm〉 [1. Pers. Pl.]

28 Keine chronologischen Angaben machen die historischen Lautlehren des Slowenischen (vgl. Ramovš 1936: 162, Greenberg 2000: 100).

29 Im Tschechischen hat der Jerwandel nach der Vokalkontraktion eingesetzt, s. Komárek 1969: 46 (§ 10.5), Lamprecht - Šlosar - Bauer 1986: 44, 46.

${ }^{30} \mathrm{Im}$ Polnischen gibt es ein relatives chronologisches Kriterium: nach dem Übergang von $e$ $>o$ vor harten Dentalen, da das $e\left(<*_{b}\right)$ nicht an diesem Übergang teilnahm (pies vs. miód). Da die nach der Christianisierung Polens im Jahre 966 entlehnten Wörter (kościót, Piotr) noch diesen Übergang zeigen, ist dies der terminus post quem, vgl. Klemensiewicz - Lehr-Spławiński - Urbańczyk 1955: 77, 112; Stieber 1975: 26 (§ 13.); Mazur 1993: 44.

31 Edition: Vintr 1985.

32 SłStp V: 530, s. v. Ogień. 
2003). Wir wollen das Material in Beispiele teilen, in denen die sekundären Jerlaute noch nicht auftreten, und in solche, in denen sie bereits vorkommen. Die erste Gruppe von Beispielen besitzt klarerweise nur beschränkte Aussagekraft. Außerdem sollen die Beispiele geographisch getrennt angeführt werden, also in bosnische, kroatische und serbische, wobei die Grenze manchmal schwer zu ziehen und nicht absolut ist.

Bosnische Beispiele sind folgende bekannt: A. Negativ: монстръ (Grabinschrift des Župans Grd, 1173-1189; Tomović 1974: 34, Nr. 5); шсмь (Urkunde des bosnischen Ban Kulin, 118933; Stojanović 1929: 2, Nr. 3, Z. 13); cmb (2x; Urkunde des bosnischen Ban Matija Ninoslav, 12344; Stojanović 1929: 7, Nr. 10, Z. 6, 11); ша.оумысль, А.оБромысль (Urkunde des Großfürsten von Hum Andrija, 1247-124935; Stojanović 1929:5, Nr. 8, Z. 20 \& Stojanović 1929:5, Nr. 8, Z. 22); B. Positiv: сьмь (Urkunde des bosnischen Ban Kulin, 1189; Stojanović 1929: 2, Nr. 3, Z. 4); сьмь (3x; Urkunde des bosnischen Ban Matija Ninoslav, 1234; Stojanović 1929: 7, Nr. 10, Z. 13, 14, 15).

Kroatische Beispiele sind folgende bekannt: A. Negativ: [P]etrъ, So|1[ъ] vêstrъ (Inschrift aus der Župa dubrovačka, 11. Jh.; Čunčić - Perkić 2009: 85, Z. 3, Z. 5-6); [мо]їтрт (Inschrift aus Povlja, 1184; Tomović 1974:34, Nr. 6); B. Positiv: es'mb (1. Pers. P1.), es'mь (1. Pers. Pl.) (Aa18, Ba6; Wiener Blätter, Beginn des 12. Jh. ${ }^{36}$ ); Zъvъnimirъ (?) (Steinplatte von Baška, ca. 1100 37 ); vъръ|l (Ba16-17, Missalefragment von Split, 12./13. Jh. ${ }^{38}$ ); pri dъvrechъ (I.24, Act 5.9), еsъmъ (VIII.1, Act 9.5), Savъ८ь (VI.2, VI.8; Act 8.1, 8.3) (Gršković-Apostolus, 12. Jh. ${ }^{39}$ ); осьмьд.єсєть, колоуд.ьрь, єсьмь (Urkunde von Povlja, 125040); og'nъ, og'nъ (2x), Pav'lь, s(ь)p(a)sьlь (Fragment der Vita der hl. Thekla, 13. Jh. ${ }^{41}$ ); ogbnni (AII16) (Fragment Nr. 30 von Krk, 13. $\mathrm{Jh}^{42}$ ).

Serbische Beispiele sind folgende bekannt: A. Negativ ${ }^{43}$ : pаставль, мысль, єсмь, мысль (Gründungsurkunde von Stefan Nemanja für das Kloster Hilandar, 1198$1199^{44}$; Trifunović - Bjelogrlić - Brajović 1986: 54, Z. 6, Z. 17, Z. 21, Z. 42 = Solo-

33 Abbildung bei Mošin 1966: 18, Tafel 13 und Đorđić 1990: 251, Tafel 22.

34 Abbildung bei Đorđić 1990: 277, Tafel 57.

35 Abbildung bei Đorđić 1990: 275, Tafel 54.

36 Edition: Jagić 1890.

37 Edition: Fučić 1982: 44(-61).

38 Edition: Štefanić 1957.

39 Edition: Jagić 1893; zu den Jerlauten vgl. Mihaljević 2000: 151.

40 Edition: Simunović - Olesch 1983: 436-440, Malić 1987, Damjanović - Kuzmić Mihaljević - Žagar 2009: 517-519. Abbildung bei Đorđić 1990: 279, Tafel 61 bzw. bei Damjanović - Kuzmić - Mihaljević - Žagar 2009: 516.

41 Vgl. Oblak 1894: 178.

42 Edition: Vajs 1907.

43 Beispiele mit nicht durchgeführter Jer-Epenthese aus dem Miroslav-Evangelium, dem Vukan-Evangelium und der Ilovička krmčija werden hier nicht angeführt.

44 Abbildung bei Mošin 1966: 21, Tafel 16 und Teilabbildung bei Đorđić 1990: 252-53, Tafel 24. 
vjev 1925: 82.13, 83.15, 84.5, 86.20); смь (Urkunde des serbischen Großžupans und Königs Stefan des Erstgekrönten, ca. 1215 ${ }^{45}$; Stojanović 1929: 3, Nr. 4, Z. 6); прнснь (Kolophon des Vukan-Evangeliums, ca. 1200; 189v31 ${ }^{46}$ ); B. Positiv: вль|хьвь (Mt 2.16; 321б3-4; G. P1.), Аьвр- (Mt 27.60, 292a2-3; Mc 15.46, 280a19; Lc 11.7, 169a14; Lc 13.25, 201a15), жрьтьвннкомь (Mt 23.20; 236б12-13), сєАь|маго (Mt 22.26; 99a8-9) (Miroslav-Evangelium, 1180-1190 47); Аь врн (Mt 25.10; 75a2-3), єсьмь/кесмь (1. P. Sg.: 10в7, Іо 6.20; 18д6, Іо 8.58; 19г15-16, Іо 10.7; 19г20-21, Іо 10.9; 20д5, Іо 9.5; 20д23, Іо 9.9; 37д12, Мt 8.9; 47г9-10, Mt 18.20; 50a6-7, Mt 14.27; 59a22, Mt 19.20; 68a13, Mt 24.5; 80a3, Lc 4.43; 149д1, Mt 24.5), ксьмь (1. P. P1.: 16в5-6, Іо 8.33), нвсьмь (Io 18.17; 169a1), мрьтьвыхь (Mt 27.64, 174д25), сєдьммую (11г3; Io 4.52) (Vukan-Evangelium, са. 120048); пртклєтьвьства, сьмь, прьклєтьвьствь (Urkunde des serbischen Königs Stefan Radoslav, 1234 ${ }^{49}$; Stojanović 1929: 11, Nr. 13, Z. 5, 11, 24); zємє入 (Urkunde des serbischen Königs Stefan Uroš I., 1254 ${ }^{50}$; Stojanović 1929: 19, Nr. 21, Z. 41); на,оложрьтьвнаґа (78r $\left.\beta 24\right)$, жрьтьвннкь (91ra12-13), Аьврнн (94ra15-16), жрьтьвннкоу (110va19-20), ньсьм' (137va16), КАєтьвннкь (182r $\beta 4-5)$, кесьм $(188 \mathrm{r} \alpha 25)$, мрьтьвь $(249 \mathrm{r} \beta 22)$, кесьмь


жрь|тьвннкь (263va10-11), мрьтьвь (271 r $\alpha 6)$, ксьмь (292r $\beta 2)$, ксь|мь (301r $\beta 3-4)$, шгьн'нын (327r $\alpha 12)$, мрьтьвна (355v $\beta 20)$, вь жрьть|вннць (364v $\alpha 21-22)$, жрьтьвннкомь (364v $\beta 18)$, мє, ьвна (373va14), вль/Хьвь $(375 \mathrm{r} \beta 24-25)$, ю|сьмь (393ra14) (Ilovička krmčija, 1262 $2^{51}$ ).

Die Schreiber von serbisch-kirchenslawischen Handschriften des 12. und 13. Jahrhunderts konnten offenkundig die Jer-Epenthese bis zu einem gewissen Grad unterdrücken. Ein anschauliches Beispiel für diese Tatsache ist das Mihanović-Homiliar (HAZU IIIc9) aus dem Ende des 13. Jh. bzw. vom Übergang des 13. zum 14. Jh. Die Handschrift schreibt fast nie sekundäre Jerlaute, nicht einmal in Wörtern wie ogənj 'Feuer', das immer als шгнь erscheint. In Einzelfällen wird dennoch der sekundäre Jerlaut geschrieben, vgl. z. В. в в $\Delta$ ьрцє (222rb2, 222rb10; 3 Reg 17.14)

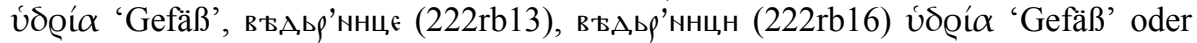
оу|гьль (102rb25-26), оугьл (177vb26) 'Kohle'.

Das Zeugnis der bosnischen, kroatischen und serbischen Sprachdenkmäler zeigt, dass die Jer-Epenthese zur Zeit der ersten erhaltenen Denkmäler bereits durchgeführt worden war. Nicht klar ist freilich, wie lange Zeit davor der Prozess zu wirken begann. Wir könnten uns hier auf die Analogie der anderen slawischen Sprachen

45 Urkunde nur in Abschrift des Dubrovniker Notars Paskal erhalten; Abbildung bei Đorđić 1990: 279, Tafel 60.

46 Stojanović 1902/1982: 4, Nr. 7, Z. 16, Trifunović 2002: 78.

47 Edition: Rodić - Jovanović 1986.

48 Edition: Vrana 1967.

49 Abbildung bei Đorđić 1990: 266, Tafel 41.

50 Abbildung bei Đorđić 1990: 270, Tafel 46.

51 Edition in: Petrović 1991. 
stützen. Am wichtigsten ist das Zeugnis der am nächsten verwandten südslawischen Sprachen. Das Altkirchenslawische kennt, wie schon erwähnt wurde, de facto noch keine Jer-Epenthese. Im Slowenischen der Freisinger Denkmäler (972-1039), d. h. spätestens gegen Ende der ersten Hälfte des 11. Jh., tritt sie bereits teilweise auf. Wir können also entweder annehmen, dass sie im Alt-Serbokroatischen, der Vorstufe der modernen Standardsprachen des Bosnischen, Kroatischen und Serbischen, ebenso bereits im 11. Jh. zu wirken begann, oder dass sie erst zu Beginn des 12. Jh. einsetzte. Die erste Variante vertrat Belić in seiner historischen Lautlehre: „Ти сугласници или сонанти развили су се већ врло рано у нашем језику, пре XII века, у ьм, ьр, ьњ, ьв, ьл, ьн итд.“ (Belić 1960: 85)..$^{52}$

Bei der Chronologie des Auftretens der Jer-Epenthese sind folgende Kriterien wesentlich:

(1) Chronologie des Schwundes der schwachen Jerlaute;

(2) Auftreten der Jer-Epenthese in den Sprachdenkmälern;

(3) Zeugnis der anderen slawischen Sprachen.

Für das Altserbokroatische sind keine Sprachdenkmäler vor dem Ende des 11. Jahrhunderts erhalten. ${ }^{53}$ In der jüngst gefundenen und veröffentlichten Steinplatte aus der Župa dubrovačka (11. Jh.; vgl. Čunčić - Perkić 2009) werden alle Jerlaute geschrieben (z. B. zъdal , Z. 1; pъ|salb, Z. 4-5). Die kroatisch-glagolitischen Wiener Blätter haben die meisten schwachen Jerlaute noch erhalten, teils in Form des vorderen Jer-Graphems, teilweise in Form eines Apostrophs. ${ }^{54}$ Jedoch kommen auch manche Wörter ohne Jerlaute vor (z. B. zlaè, Aa3; mnogie, Bb17) ${ }^{55}$ Ein ähnliches Bild zeigt die Steinplatte von Baška aus den ersten Jahren des 12. Jahrhunderts (Jerlaut erhalten: hrъvatıskъï [Z. 3], vъ [Z. 5, 11, 13], zъ|dahъ [Z. 9-10], crěkъvъ [Z. 10], kъneza [Z. 11], otočъci [Z. 13]; Jerlaut geschwunden: [o]tca [Z. 1], pisah [Z. 2], $d n i$ [Z. 4, 12], sdě [Z. 8], s [Z. 10]). Deswegen ist es wahrscheinlich, dass die schwa-

52 Überflüssig ist eine erste, vorhistorische Jer-Epenthese (zuerst vorgeschlagen in Holzer 2005: 48; s. auch Matasović 2008: 147, Fn. 199), die bloß auf Grund einiger Akzentunterschiede angesetzt wurde (skr. döbar vs. òganj), welche auch anders erklärt werden können. Vgl. ebenso ablehnend dazu Kortlandt 2006: 34, 37.

53 Die Inschrift von Temnić (Temnićki natpis; 10. Jh. bzw. 11. Jh.; Stojanović 1913; Abbildung in: Đorđić 1990: 241, Tafel 13) kann hier außer Betracht bleiben, da sie keine einschlägigen Beispiele bietet (vgl. immerhin den Namen нракर̄ь, erwartungsgemäß ohne Schwa-Epenthese). - Das aksl. Tetraevangelium des Codex Marianus kann ebensogut westbulgarisch wie serbisch sein, vgl. Koch 1987: 88. - Die lateinschriftliche Wiedergabe der starken Jerlaute in Personen- und Ortsnamen mit $\langle\mathbf{e}\rangle$ oder $\langle i\rangle$ aus der ersten Hälfte des 11. Jh. besitzt für deren Entwicklung eine begrenzte Relevanz, da diese Grapheme sowohl die ursprünglichen Jerlaute als auch deren Reflex als einheitlichen Schwalaut bezeichnen konnten.

54 Auf der Steinplatte von Valun aus dem Ende des 11. Jh. wird der schwache Jerlaut der ersten Silbe noch geschrieben: $v ъ[n u] k b$ (die zweite Silbe ist ausgelassen und kann auf Grund des lateinischen Textes rekonstruiert werden; s. Fučić 1982: 354).

55 Jagić 1890: 29. 
chen Jerlaute im Urkroatischen - und analog dazu in der Vorstufe des Bosnischen und Serbischen - im Laufe des 11. Jh. geschwunden sind.$^{56}$ Dies ist der terminus post quem für die Entstehung der Jer-Epenthese. Die ersten Beispiele für die JerEpenthese liefern wieder die kroatisch-glagolitischen Texte, besonders zwei Beispiele aus den Wiener Blättern (das Beispiel Zъvъnimirz auf der Steinplatte von Baška ist $\mathrm{m}$. M. nach nicht sicher, da der Text auch sonst Beispiele mit unetymologischen Jerlauten kennt, vgl. z. B. kъrainu, Z. 11, Fučić 1982: 44). Die Frage, ob man die Entstehung der Jer-Epenthese ins Ende des 11. Jh. oder in den Beginn des 12. Jh. verlegt, hängt davon ab, wie man die Beispiele mit nicht durchgeführter Epenthese aus dem 12. Jh. bewertet. Sieht man sie als archaisierende schriftsprachliche (kirchenslawische) Formen an, dann steht dem Ansatz der Entstehung der JerEpenthese im 11. Jh. nichts entgegen. Wertet man sie aber als sprachreale Formen, dann kann man den Prozess der Epenthese als allmählich auftretend interpretieren und wird die Entstehung der Epenthese in die erste Hälfte des 12. Jh. verlegen. Weniger wichtig erscheint mir das Zeugnis der verwandten südslawischen Sprachen. Es ist möglich, dass sich diese Sprachen bei diesem Prozess stark unterschieden haben. Darauf gibt auch die vorher angeführte starke Differenz bei der Durchführung der Epenthese in den einzelnen slawischen Sprachen einen Hinweis: während das Tschechische sie z. B. bis heute nicht ausnahmslos durchgeführt hat, geht das eng verwandte Slowakische in dieser Hinsicht mit seiner ausnahmslosen Durchführung mit den südslawischen Sprachen parallel. Deshalb kann das Slowenische, wie die Freisinger Dekmäler zeigen, diesen Prozess viel früher durchgeführt haben als das verwandte Kroatische bzw. Serbokroatische.

\section{Literatur}

Belić 1960: Александар Белић, Основи историје српскохрватског језика, I. Фонетика, Београд

Beneševič 1906: Древне-славянская кормчая XIV титулов без толкований. Труд В. Н. Бенешевича, Том первый, Санктпетербург

BER 1: $\quad$ Български етимологичен речник, 1, София 1971

Cejtlin - Večerka - Bláhová 1994: Р. М. Цейтлин - Р. Вечерка - Э. Благова, Старославянский словарь (по рукописям X - XI веков), Москва

Čunčić - Perkić 2009: Marica Čunčić - Marta Perkić, Hrvatski glagoljski natpis Župe dubrovačke iz 11. stoljeća, Slovo 59, 77-122

\footnotetext{
56 So ähnlich auch in der Tafel bei Matasović 2008: 171: „1050“. Zu früh datiert Shevelov den Jer-Ausfall im Serbokroatischen, da er weniger die Denkmäler (die damals teilweise noch nicht bekannt waren), sondern mehr die Situation im benachbarten Slowenischen berücksichtigt: ,As written records of SC do not reach farther back than the eleventh century, they show only that $\mathrm{SC}$ did not have jers at that time. But there is no reason to doubt that the jers were lost in SC not much more tardily than in Sn." (Shevelov 1964: 459, $\S 29,12)$.
} 
Damjanović - Kuzmić - Mihaljević - Žagar 2009: Antologija hrvatskih srednjovjekovnih djela, in: J. Bratulić, S. Damjanović, A. Frančić, B. Kuzmić, J. Lisac, R. Matasović, M. Mihaljević, M. Žagar, Povijest hrvatskoga jezika, 1. knjiga: Srednji vijek, Zagreb, 457-541

Derksen 2008: $\quad$ Rick Derksen, Etymological Dictionary of the Slavic Inherited Dictionary, Leiden - Boston

Diels 1932:

Paul Diels, Altkirchenslavische Grammatik mit einer Auswahl von

Duma 1990:

Texten und einem Wörterbuch, I. Teil: Grammatik, Heidelberg Jerzy Duma, Rozwój sekundarnego wokalizmu typu sъm, ogъn, v’atъr $<*_{\text {jesmb }}$ *ognb, *větrb we wschodniej grupie dialektów południowosłowiańskich, in: Językowe studia bałkanistyczne. Tom II, Wrocław Warszawa - Kraków, 27-55 (+ 16 kart)

Đorđić 1990:

Петар Ђорђић, Историја српске ћирилице. Палеографско-филолошки прилози, ${ }^{3}$ Београд

Elenski 1960:

ESJS 13:

Flier 1993:

Йордан Еленски, Редуцированные гласные в Святославовом изборнике 1073 года, Годишник на Софийския университет, Филологически факултет, т. LIV, 1 (1959/60 [1960]), 625-699 [= 3-77]

Etymologický slovník jazyka staroslověnského, 13: rasti - sice, Praha

Michael Flier, Final Sonorant clusters in East Slavic, in: American contributions to the eleventh international congress of slavists (Bratislava, August-September 1993), 251-269

Fučić 1982:

Branko Fučić, Glagoljski natpisi, Zagreb (Jugoslavenska akademija znanosti i umjetnosti. Razred za filologiju i razred za likovne umjetnosti)

Gebauer 1894: $\quad$ Jan Gebauer, Historická mluvnice česká. Díl I. Hláskosloví, V Praze a ve Vídni

Gebauer 1903-1916: Jan Gebauer, Slovník staročeský, I (A-J), II (K-netbalivost), V Praze

Georgieva 2003: $\quad$ Златоструй от XII век. Увод и научно разчитане на текста Тодорка Георгиева, Силистра

Golyšenko - Dubrovina 1967: В. С. Голышенко - В. Ф. Дубровина, Синайский Патерик, Москва

Greenberg 2000: $\quad$ Marc L. Greenberg, A Historical Phonology of the Slovene Language, Heidelberg

Holzer 2005:

Georg Holzer, Zur relativen Datierung prosodischer Prozesse im Gemeinslavischen und frühen Kroatischen, Wiener Slavistisches Jahrbuch $51,31-71$

Il'inskij 1912:

Г. А. Ильинский, Слепченский апостол XII века, Москва

Issatschenko 1970:

Alexander V. Issatschenko, East Slavic Morphophonemics and the Treatment of the Jers in Russian: A Revision of Havlík's Law, International Journal of Slavic Linguistics and Poetics 13, 73-124

Issatschenko 1980: $\quad$ Alexander Issatschenko, Geschichte der russischen Sprache, 1. Band: Von den Anfängen bis zum Ende des 17. Jahrhunderts, Heidelberg

Jagić 1890: Vatroslav Jagić, Glagolitica. Würdigung neuentdeckter Fragmente, Denkschr. d. kais. Akad. d. W., phil.-hist. Cl., XXXVIII, Wien

Jagić 1893: $\quad$ Vatroslav Jagić, Grškovićev odlomak glagolskog apostola, Starine 26, 33-161

Jagić 1898: $\quad$ Vatroslav Jagić, Evangelium Dobromiri. Ein altmacedonisches Denkmal der kirchenslavischen Sprache des XII. Jahrhunderts. Grammatisch und kritisch beleuchtet. I. Grammatischer Theil. Mit drei Tafeln, Sitzungsberichte der kaiserlichen Akademie der Wissenschaften in Wien, Phil.-hist. Cl., Band CXXXVIII, 2. Abh., Wien, 1-80 + I-III

Janin - Zaliznjak 1994: Валентин Л. Янин \& Андрей А. Зализняк: Берестяные грамоты из новгородских раскопок 1990-1993 гг., Вопросы языкознания 1994/3, 3-22

Klemensiewicz - Lehr-Spławiński - Urbańczyk 1955: Z. Klemensiewicz - T. Lehr-Spławiński - S. Urbańczyk, Gramatyka historyczna języka polskiego, Warszawa 
Koch 1987:

Komárek 1969:

Koneski 1967:

Kopečný 1981:

Kortlandt 2006:

Krajčovič 1975:

Kul'bakin 1898:

Kul'bakin 1925:

Lamprecht - Šlosar - Bauer 1986: Arnošt Lamprecht - Dušan Šlosar - Jaroslav Bauer, Historická mluvnice češtiny, Praha

Lencek 1982:

Malić 1987:

Mareš 1977:

Mareš 1981-1982:

Mareš 1991:

Matasović 2005:

Matasović 2008:

Mayrhofer 1986:

Mazur 1993:

Meyer 1923a:

Meyer 1923b:

Mihaljević 2000:

Mihaljević 2003:

Miklosich 1862-1865: Franz Miklosich, Lexicon Palaeoslovenico-Graeco-Latinum, ${ }^{2}$ Vindobonae

Christoph Koch, Zum Wechsel der Imperativformen aksl. sędi sęděte und sědi sěděte. Mit einem Beitrag zur Herkunft des Codex Marianus, Zeitschrift für Slavische Philologie XLVII, 63-97

Miroslav Komárek, Historická mluvnice česká. Díl I. Hláskosloví, Praha

Блаже Конески, Историја на македонскиот јазик, Скопје (= Блаже Конески, Избрани дела во седум книги)

František Kopečný, Základní všeslovanská slovní zásoba, Praha

Frederik Kortlandt, On the relative chronology of Slavic accentual developments, Wiener Slavistisches Jahrbuch 52, 25-41

Rudolf Krajčovič, A Historical Phonology of the Slovak Language, Heidelberg

Степан М. Кульбакин: Заметки о языке и правописании Волканова Евангелия, Известия ОРЯС $3.4,1140-1172$

Степан М. Куљбакин, Палеографска и језичка испитивања о Мирослављевом јеванђељу, Сремски Карловци (СКА - Посебна издања, књ. LII. Философски и филолошки списи, књига 13)

Rado L. Lencek: The Structure and History of the Slovene Language, Columbus/Ohio

Dragica Malić, Povaljska listina. Latinička transkripcija teksta, in: Brački zbornik 15 (obljetnica povaljske listine i praga 1184-1984), Supetar, 11-16

Фрањо В. Мареш, Силабичне ликвиде у српскохрватском и у чешком језику. Zbornik radova - povodom 70. godišnjice života akademika Jovana Vukovića (= ANUBiH, Posebna izdanja, knj. XXXIV, odj. društvenih nauka, knj. 6), Sarajevo, 217-222

Франтишек В. Мареш, Вокализацијата на македонските силабични сонанти и нејзиното значење за фонолошкиот систем, Македонски јазик 32-33, 441-446

František V. Mareš, Vom Urslavischen zum Kirchenslavischen, in: Peter Rehder, Hrsg., Einführung in die slavischen Sprachen, ${ }^{2}$ Darmstadt, $1-19$

Ranko Matasović, The Centum Elements in Balto-Slavic, in: G. Meiser - O. Hackstein, Hrsg., Sprachkontakt und Sprachwandel. Akten der XI. Fachtagung der Indogermanischen Gesellschaft, 17.-23. September 2000, Halle an der Saale, Wiesbaden, 363-374

Ranko Matasović, Poredbenopovijesna gramatika hrvatskoga jezika, Zagreb

Manfred Mayrhofer, Indogermanische Grammatik, Band I/2: Lautlehre [Segmentale Phonologie des Indogermanischen], Heidelberg

Jan Mazur, Geschichte der polnischen Sprache, Frankfurt/M. - Berlin - Bern - New York - Paris - Wien

Karl H. Meyer, Historische Grammatik der russischen Sprache. Erster Band: Einleitung, Laut-, Formen- und Akzentlehre, Bonn

Karl H. Meyer: Zur Entstehung der sekundären Halbvokale im Ostslavischen, Archiv für Slavische Philologie 38, 250-257

Milan Mihaljević, Die Jer-Zeichen in den ältesten kroatisch-glagolitischen Fragmenten, in: H. Miklas, Hrsg., Glagolitica. Zum Ursprung der slavischen Schriftkultur, Wien (ÖAW, Phil.-hist. Kl., Schriften der Balkankommission, Philol. Abt., 41), 150-163

Milan Mihaljević, Fonološki sustav najstarijih hrvatskoglagoljskih fragmenata, in: Р. Божилова, Българи и хървати през вековете 2 , 
Mirčev 1978: К К Кирил Мирчев, Историческа граматика на българския език, София ${ }^{2} 1978$

Ivanova-Mirčeva - Charalampiev 1999: Дора Иванова-Мирчева - Иван Харалампиев, История на българския език, София

Mošin 1966: Владимир Мошин, Палеографски албум на јужнословенското ки-

Oblak 1894: $\quad \begin{aligned} & \text { Vatroslav Oblak, Die Halbvocale und ihre Schicksale in den sü } \\ & \text { schen Sprachen, Archiv für slavische Philologie XVI, 153-197 }\end{aligned}$ рилско писмо, Скопје

Olesch 1983, 1984: $\quad$ Reinhold Olesch, Thesaurus linguae dravaenopolabicae, I (A - O), III $(\mathrm{T}-\mathrm{Z}), \mathrm{Köln}-\mathrm{Wien}$

Pauliny 1958: $\quad$ Eugen Pauliny, Zur Entwicklung der sog. Nebensilben im Slowakischen, in: Mélanges linguistiques offerts à E. Petrovici (Cercetări de lingvistică 3, supliment), Bucureşti, 369-373

Pauliny 1963:

Petrović 1991:

Eugen Pauliny, Fonologický vývin slovenčiny, Bratislava

Законоправило или Номоканон Светога Саве. Иловички препис 1262. године. Приредио и прилоге написао М. М. Петровић, Београд

Popovski 1989: $\quad$ Josif Popovski, The Pandects of Antiochus. Slavic Text in Transcription, Полата кZnнгопнсьнаң 23/24

Ramovš 1936:

Reinhart 2002:

Fran Ramovš, Kratka zgodovina slovenskega jezika, Ljubljana

Johannes Reinhart, Sekundarni polglasniki v slovenščini in v drugih slovanskih jezikih, in: Historizem v raziskovanju slovenskega jezika, literature in kulture (Mednarodni simpozij Obdobja [18] - Metode in zvrsti, Ljubljana, 9.- 11.12.1999), Ljubljana, 285-293

Rešetar 1921: $\quad$ Milan Rešetar, Sekundarni poluglas u srpskohrvatskom književnom jeziku, Прилози за књижевност, језик, историју и фолклор 1, 238251

Rodić - Jovanović 1986: Никола Родић - Гордана Јовановић, Мирослављево јеванђеље. Критичко издање, Београд

Rozwadowski 1915: Jan Rozwadowski, Historyczna fonetyka czyli głosownia języka polskiego, in: Język polski i jego historya z uwzględnieniem innych języków na ziemiach polskich, Kraków, Część I, 289-422

Schenker 1993:

Alexander M. Schenker, Proto-Slavonic, in: B. Comrie - G. C. Corbett, eds., The Slavonic Languages, London - New York, 60-121

Schenker 1995: $\quad$ Alexander M. Schenker, The Dawn of Slavic. An Introduction to Slavic Philology, New Haven - London

Schuster-Šewc 1988: Heinz Schuster-Šewc, Historisch-etymologisches Wörterbuch der

Shevelov 1964: ober- und niedersorbischen Sprache, 22 (wołoj - zahorić), Bautzen

Shevelov 1979:

George Y. Shevelov, A Prehistory of Slavic. The Historical Phonology of Common Slavic, Heidelberg

SJS IV:

George Y. Shevelov, A Historical Phonology of the Ukrainian Language, Heidelberg

SłStp V:

SłStp IX:

Snoj 2003:

Solovjev 1925: Slovník jazyka staroslověnského - Lexicon linguae palaeoslovenicae, IV $(c-v)$, Praha 1997

Słownik staropolski, Tom V (N - Ó), Warszawa - Wrocław - Kraków 1965-1969

Słownik staropolski, Tom IX (Ściadły - Używowanie), Wrocław Warszawa - Kraków - Gdańsk - Łódź, 1982-1987

Marko Snoj, Slovenski etimološki slovar, Ljubljana (Druga, pregledana in dopolnjena izdaja)

Александар В. Соловјев, Хиландарска повеља великог жупана Стефана (Првовенчаног) из године 1200-1202, Прилози за књижевност, језик, историју и фолклор 5, 62-89

Stanislav 1956: Ján Stanislav, Dejiny slovenského jazyka, I (Úvod a hláskoslovie), Bratislava

Stieber 1973: $\quad$ Zdzisław Stieber, A Historical Phonology of the Polish Language, Heidelberg 
Stojanović 1902/1982: Љубомир Стојановић, Стари српски записи и натписи, књ. 1, Београд 1982 (= 1902; Књигу приредио Сима Ћирковић)

Stojanović 1913: Љубомир Стојановић, Темнићки натпис X-XI века (у Народном Музеју у Београду бр. 2667), Јужнословеснки Филолог I/1-2, 4-20

Stojanović 1929: Љубомир Стојановић, Старе српске повеље и писма. Књига I: Дубровник и суседи његови. 1, Београд (СКА. Зборник за историју, језик и књижевност српског народа, Прво одељење: Споменици на српском језику, XIX)

Šachmatov 1915: Александр А. Шахматов, Очерк древнейшего периода истории русского языка, Петроград

Šimunović - Olesch 1983: Petar Šimunović - Reinhold Olesch, Hrsg., Čakavisch-deutsches Lexikon. Teil III: Čakavische Texte, Köln - Wien

Štefanić 1957: $\quad$ Vjekoslav Štefanić, Splitski odlomak glagoljskog misala starije recensije, Slovo 6-8, 54-133

Tomović 1974: Гордана Томовић, Морфологија ћириличких натписа на Балкану, Београд (Историјски институт, Посебна издања, књ. 16)

Trifunović 2002: Ђорђе Трифуновић, Запис старца Симеона у Вукановом јеванђељу. Издање текста, Прилози за књижевност, историју и фолклор 67/1-4 (2001), 63-85

Trifunović - Bjelogrlić - Brajović 1986: Ђорђе Трифуновић - Весна Бјелогрлић - Ирена Брајовић, Хиландарска оснивачка повеља светога Симеона и светога Саве, Осам векова Студенице. Зборник радова, Београд, 4960 (+ 1 Abb.)

Vaillant 1950: $\quad$ André Vaillant, Grammaire comparée des langues slaves, Tome I: Phonétique, Paris

Vaillant 1964:

Vaillant 1974:

André Vaillant, Manuel du vieux-slave. Tome 1: Grammaire, ${ }^{2}$ Paris

Vajs 1907: $\quad$ La formation des noms, Paris André Vaillant, Grammaire comparée des langues slaves, Tome IV: La formation des noms, Paris Evangelistae fragmenta glagolitica, Slavorum litterae theologicae III, Praha, 123-143

Vintr 1985: Josef Vintr, Žaltář muzejní se staročeskými glosami - Edice a problém vzniku, in: Litterae slavicae medii aevi (Francisco Venceslao Mareš sexagenario oblatae), München, 401-424

Vrana 1967: Јосип Врана, Вуканово еванђеље, Београд

Wątróbska 1987: Halina Wątróbska, The Izbornik of the thirteenth century, cod. Leningrad, GPB, Q.p.I.18, полата къннгопнсьнаґа 19/20

Zaliznjak 1993: Андрей А. Зализняк, Лингвистические исследования и словоуказатель, in: В. Л. Янин - А. А. Зализняк, Новгородские грамоты на береста. Из раскопок 1984-1989 годов, Москва, 191-343

Zaliznjak 1995: $\quad$ Андрей А. Зализняк, Древненовгородский диалект, Москва

Zaliznjak - Janin 2001: Андрей А. Зализняк - Валентин Л. Янин, Новгородский кодекс первой четверти XI в. - древнейшая книга Руси, Вопросы Языкознания 5, 3-25

A bstract: The Chronology of the Origin of Secondary Jers in Serbocroatian (Bosnian, Croat and Serbian).The paper tries to determine the time of the origin of secondary jers in the prehistory of the Bosnian, Croat and Serbian language. The epenthesis of schwas $(=\mathrm{se}-$ condary jers) between consonants and word-final - sometimes: syllable-final - sonorants became necessary after the loss of word-final (syllable-final) jers in the prehistory of the Slavic languages. This loss can be dated to the $10^{\text {th }}$ and $11^{\text {th }}$ centuries. Contemporary Slavic languages differ with regard to the generality of the rule of epenthesis: some do not know of any exceptions (the South Slavic languages, Slovak), some do still allow certain word-final consonant-sonorant clusters (e.g. Russian, but above all Czech and Polish). The problem in determining the chronology of the process in the history of Serbocroat (= Bosnian, Croat and 
Serbian) is caused by the scarcity of old written documents: usually charters, inscriptions or manuscripts. It is attempted to gather a complete range of relevant examples from stone inscriptions (the first ones in Glagolitic script dating from the end of the $11^{\text {th }}$ cent., the first ones in Cyrillic script from the second half of the $12^{\text {th }}$ cent.), charters (the first ones in Cyrillic script from the second half of the $12^{\text {th }}$ cent.) and manuscripts (the first fragments in Glagolitic script dating from the beginning of the $12^{\text {th }}$ cent., the first manuscripts in Cyrillic script from the second half of the $12^{\text {th }}$ cent.).

The documentary evidence allows us to date the process of schwa epenthesis to the end of the $11^{\text {th }}$ or to the beginning of the $12^{\text {th }}$ cent. The Old Serbocroat language does not seem to show any chronological difference of this process in Bosnia, Croatia or Serbia. Among the South Slavic languages, the language in which the process started first is Slovene (the end of the $10^{\text {th }}$ or the beginning of the $11^{\text {th }}$ cent.), the other languages following later (Bulgarian in the $12^{\text {th }}$ century, Serbocroat in the $11-12^{\text {th }}$ cent.).

Ke y w ords: secondary jers, schwa epenthesis, history of the Bosnian, Croat and Serbian language, Old Serbocroat charters, inscriptions and manuscripts in Glagolitic and Cyrillic script

Johannes Reinhart

Institut für Slawistik der Universität Wien

Universitätscampus AAKH, Hof 3

Spitalgasse 2, 1090 Wien, Österreich

johannes.reinhart@univie.ac.at 